\title{
Contribution of Suckling Stimulation to the Daily Periodic Display of Nursing Behavior in Non-Lactating Virgin Rabbits
}

\author{
Gabriela González-Mariscal ${ }^{1 *}$, Ana Celia Lemus ${ }^{2}$ and Raúl Aguilar-Roblero ${ }^{3}$
}

${ }^{1}$ Research Center for Animal Reproduction CINVESTAV- Autonomous University of Tlaxcala, Mexico

${ }^{2}$ Master of Biological Sciences, Tlaxcala Center Behavioral Biology, Autonomous University of Tlaxcala, Mexico

${ }^{3}$ Institute of Cellular Physiology, National Autonomous University of Mexico, Mexico

\begin{abstract}
A female rabbit (does) nurse once a day for three min with circadian periodicity. This timing is controlled by the amount of suckling stimulation received as small litters (2-4 kits) disrupt nursing periodicity and increase the duration of nursing bouts. Yet, as suckling induces: a) the secretion of oxytocin and prolactin and b) milk ejection, the relative contribution of those two types of factors to the daily timing of nursing needs to be independently explored. Therefore, the objective of the present work was to determine the relevance of milk output for the circadian display of rabbit nursing behavior. Methods: We used the model of anosmic virgins, as they can be induced to behave maternally (by lesioning the olfactory epithelium), they allow suckling from (foster) kits, but they are unable to produce milk. Does were given five foster kits, aged 1-5 days, placed inside a transparent nest box within the maternal cage, and replaced daily. The does' behavior was recorded continuously for 15 days through a video system allowing us full view of the animals. Results: By day 6 post-lesion $70 \%$ of virgins (i.e., 14/20) were entering the nest box, adopting a crouching posture over the litter, allowing suckling, and leaving ca. $3 \mathrm{~min}$. later. $55 \%$ (i.e., 11/20) of lesioned virgins displayed nursing behavior with a ca. $24 \mathrm{hr}$ periodicity, as determined by a Rayleigh analysis (3 does) or a linear regression (8 does). Conclusions: a) daily periodicity of nursing behavior can occur regardless of milk output or a preceding pregnancy; b) such factors, however, contribute to the display of a single daily episode of circadian nursing behavior in most does.
\end{abstract}

Keywords: Circadian rhythms; Nursing; Maternal behavior; Rabbits; Lactation; Suckling; Oxytocin; Olfactory epithelium

\section{Introduction}

Lactating rabbits (does) nurse the young inside the maternal nest only once a day, for around three minutes [1-3] with circadian periodicity, under continuous light [4] or light: dark conditions $[5,6]$. These characteristics are modulated by suckling stimulation as rabbit does nursing four kits or less enter the maternal nest several times a day [6] and they stay inside it for more than three min [7-9]. Accordingly, a maximal expression of the PER1 protein (product of the clock gene per1) is observed in specific regions of the rabbit forebrain at eight hrs post-suckling, independently of the time of day at which mothers nursed [10]. Taken together, the above findings suggest that the timing of circadian nursing behavior and the time inside the nest box rely on suckling stimulation. Indeed, pre-emptying the mammary glands of milk (by suckling a foster litter under anesthesia) does not antagonize the doe's entrance into the nest box to nurse her own kits [11] Moreover, virgin rabbits can be induced to behave maternally by lesioning the olfactory epithelium with $\mathrm{ZnSO}_{4}$ [12] despite their incapacity to produce milk. When foster kits are introduced into the nest box at a specific time of day such anosmic virgins will almost immediately jump inside and adopt a crouching posture over the litter. The kits will then start searching for the doe's nipples and initiate suckling guided by the so-called mammary pheromone [13], which is produced by lactating mothers and also by virgins $[14,15]$. After ca. 3 min of receiving suckling stimulation from the foster litter, and despite the lack of milk output, anosmic virgins will jump out of the box, as do regular lactating mothers. This evidence shows that milk output is irrelevant for determining the female's motivation to enter the nest box and the time she spends inside it. Yet, such information fails to reveal if milk output contributes to the spontaneous circadian display of nursing because the cited studies only measured the doe's willingness to nurse and the time she spent inside the nest box $[8,11,12]$. Thus, in the present work we hypothesized that, if milk output is irrelevant for determining the circadian display of nursing in rabbits, anosmic virgins provided with a (foster) suckling litter (larger than four pups) would show a daily pattern of circadian nursing behavior.

\section{Materials and Methods}

Animals and housing conditions: Virgin New Zealand white adult female domestic rabbits (3.5-4.5 Kg body weight) bred in our colony was used. They were housed in individual wire mesh maternal cages (90 cm long x $60 \mathrm{~cm}$ wide $\mathrm{x} 40 \mathrm{~cm}$ high) that contained a transparent acrylic nest box $(50 \mathrm{~cm}$ long $\mathrm{x} 30 \mathrm{~cm}$ wide $\mathrm{x} 32 \mathrm{~cm}$ high). Conditions inside the vivarium were: controlled light (14:10 L:D; lights-off at $21: 00 \mathrm{~h}$ ) and natural temperature $\left(13-25^{\circ} \mathrm{C}\right)$. Water and Purina rabbit pellets were provided ad libitum every day between 07:00 and 08:00 h. Throughout this work animal care complied with the Law for the Protection of Animals (Mexico) and with international guidelines regarding animal research [16].

Lesion to the olfactory epithelium: Females were made anosmic as described earlier [10], following the procedure of Mulvaney and

*Corresponding author: Gabriela GM, Centro de Investigación en Reproducción Animal, CINVESTAV-Universidad Autónoma de Tlaxcala; Km 10.5 Autopista San Martín Texmelucan, Campus UAT, Ixtacuixtla, Tlaxcala 90120, Mexico, Tel: +52248-48-16020; Fax: +52-248-48-15476; E-mail: gabygmm@gmail.com

Received October 31, 2015; Accepted November 21, 2015; Published November 27, 2015

Citation: González-Mariscal G, Lemus AC, Aguilar-Roblero R (2015) Contribution of Suckling Stimulation to the Daily Periodic Display of Nursing Behavior in Non-Lactating Virgin Rabbits. J Neurol Neurophysiol 6: 327. doi:10.4172/21559562.1000327

Copyright: (c) 2015 González-Mariscal G, et al. This is an open-access article distributed under the terms of the Creative Commons Attribution License, which permits unrestricted use, distribution, and reproduction in any medium, provided the original author and source are credited. 
Heist [17]. Briefly, females were lightly anesthetized with ketamine (1 $\mathrm{mg} / \mathrm{kg}$; Imalgen; Rhone-Merieux, Mexico) and xylazine hydrochloride (rompun; $25 \mathrm{mg} / \mathrm{Kg}$; Beyer, Mexico). 1.0-1.5 ml of $5 \% \mathrm{ZnSO}_{4}(\mathrm{n}=20)$ or saline $(\mathrm{n}=8)$ was then infused into each nostril (using polyethylene tubing, Clay Adams PE 60; O.D=1.22 $\mathrm{mm}$; I.D=0.76 mm) while rabbits were gently held in the supine position. Two minutes later does were held with their head down to allow the solution to flow out of the nostrils and thus minimize spread to the oral cavity. Rabbits were then returned to their home cages.

Olfactory perception and ambulation tests: To verify that the infusion of $\mathrm{ZnSO}_{4}$ induced anosmia, while the infusion of saline did not, we used the olfactory discrimination test reported earlier [12]. Females were placed inside a square wire mesh arena $(1.2 \mathrm{~m} / \mathrm{side}$ x $60 \mathrm{~cm}$ high, with the floor raised $10 \mathrm{~cm}$ above the ground) which had a painted grid dividing the floor into nine squares. Two glass jars containing water or freshly collected male urine were placed under two opposing corners of the arena. We counted, for the next $10 \mathrm{~min}$, the number of times the rabbit sniffed each of the jars. To determine non-specific effects provoked by the chemical lesion to the olfactory epithelium, we simultaneously counted the number of times the rabbit crossed any of the lines painted on the floor (ambulation in an open field). These tests were made on two consecutive days before the infusion of $\mathrm{ZnSO}_{4}$ (or saline; baseline) and again on post-infusion days 1 and 2. To confirm the recovery of olfactory function at the end of the experiment these tests were performed again on day 18 .

Nursing behavior measurement: Starting on post-infusion day 3 video cameras were installed inside the vivarium and connected, via underground cables, to a computer placed in a different room. The transmitted images were recorded directly onto the hard drive, a procedure used in our previous study [6] that allowed us to review the videos off line at any time of day. Six kits from a lactating mother of our colony were placed inside the nest box of each experimental virgin at 10:00 $\mathrm{h}$ and remained there for the next $24 \mathrm{~h}$. The kits were then returned to their mother for nursing and replaced with new litters of the same age. These had been fed their own mothers a few hours earlier. This procedure was repeated daily for five days after which new litters of newborn kits were used. Thus, the experimental virgins were continuously exposed to foster kits, aged 1-5 days. Because the nest box used was transparent (see above) we were able to have a full view of the behavioral interactions between virgins and foster litters at any time, particularly if the kits suckled, presumably guided by the "nipple pheromone", as described in our earlier study [12]. The following parameters were recorded without interruption for the following 15 days: a) hour of day when the doe entered the nest box and adopted a crouching posture (indicative of nursing behavior) over the litter; $b$ ) duration of time spent inside the nest box at each visit (determined by subtracting the time of exit from the time of entrance).

Statistical analysis: To compare the number of sniffs and crossings (ambulation in an open field) shown before vs after the infusion of $\mathrm{ZnSO}_{4}$ (or saline) a Wilcoxon test was performed [18]. To determine the vector that best described a female's individual time for displaying nursing behavior across days 1-15 a Rayleigh test for randomness [19] was performed. From this analysis we derived the phase angle and rho of every individual vector. Only females that showed nursing behavior on at least five days were included in the population vector, which was obtained from the Rayleigh analysis of the mean phase angle vector of each individual. When this criterion was not met, and visual inspection of the actograms revealed an apparently drifting (as free running) daily pattern of nursing behavior, a linear regression analysis was performed on the time of display of this activity. This allowed us to determine, for each individual, the period and the significance of $r$ from the lines adjusted to such daily patterns.

\section{Results}

Figure 1 shows that in females infused with saline the number of sniffs directed towards urine was significantly higher than those directed to water. These differences were evident on the days preinfusion and persisted until the last day of testing, indicating that the infusion of saline did not induce anosmia. In contrast, does infused with $\mathrm{ZnSO}_{4}$ directed more sniffs towards urine before the infusion, were unable to discriminate between these stimuli on post-infusion days 1 and 2, and recovered this capacity by day 18 (Figure 2). These findings confirm that, as reported previously $[12,17]$ the infusion of $\mathrm{ZnSO}_{4}$ provokes a degeneration of the olfactory epithelium, which leads to anosmia, followed by a regeneration of such tissue which, in turn, allows the recovery of function. Ambulation in an open field (Figure 3) significantly declined with respect to baseline on post-infusion days 1 and 2 in both experimental groups but had fully recovered by day 18 .

Infusion of $\mathrm{ZnSO}_{4}$ promoted the expression of nursing behavior as up to $70 \%$ of does in such group (i.e., 14/20) showed this response by day 6 (Figure 4). In contrast, no saline-infused rabbit entered the nest box and crouched over the litter on any day of testing, confirming that virgin does are not 'spontaneously maternal' unless they become anosmic. Nursing behavior in anosmic virgins, however, was expressed in an irregular fashion (Table 1). For instance, the latency for the onset of this activity (relative to the days of exposure to kits) ranged from 1-6 days and the maximal number of consecutive days on which an anosmic rabbit showed nursing behavior ranged from 2-13. That is, in contrast to 'regular' nursing mothers, which nurse every day from parturition onwards, anosmic virgins performed nursing behavior on some days and not on others.

A Rayleigh analysis revealed that the values of rho (indicating the direction of the vector describing the most likely time of nursing behavior) were statistically significant for three females. Indeed, the actograms of such does show that their nursing behavior occurred usually once a day, during the dark phase (Figure $5 \mathrm{~A}, \mathrm{~B}, \mathrm{C}$ ). Other rabbits, by contrast, entered the nest box several times across the day (Figure $6 \mathrm{~A}, \mathrm{~B}, \mathrm{C}$ ). When double-plotted their actograms revealed that entrances into the nest box on any given day did not occur randomly but in a timed manner, during a restricted portion of the

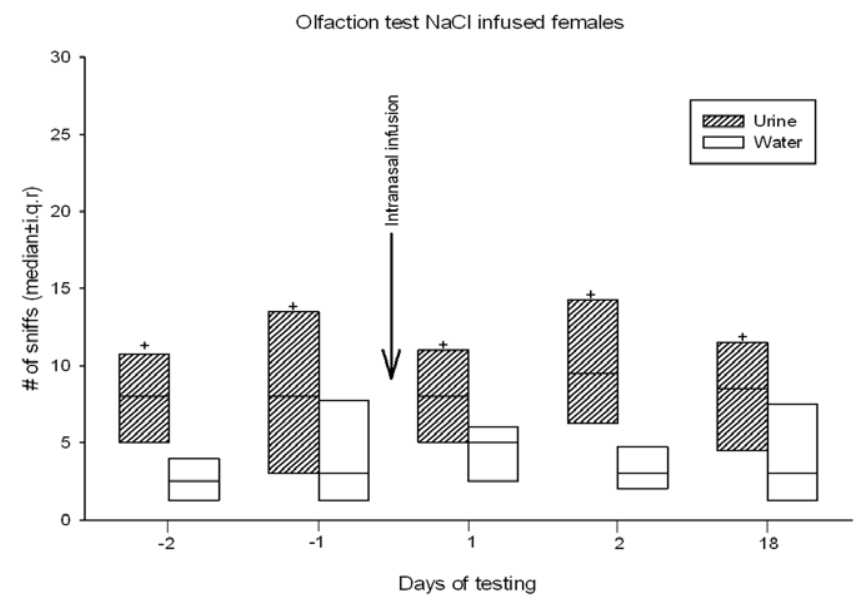

Figure 1: Number of sniffs directed at water or urine before and after the infusion of $\mathrm{NaCl} .+p<0.05$ vs water. 


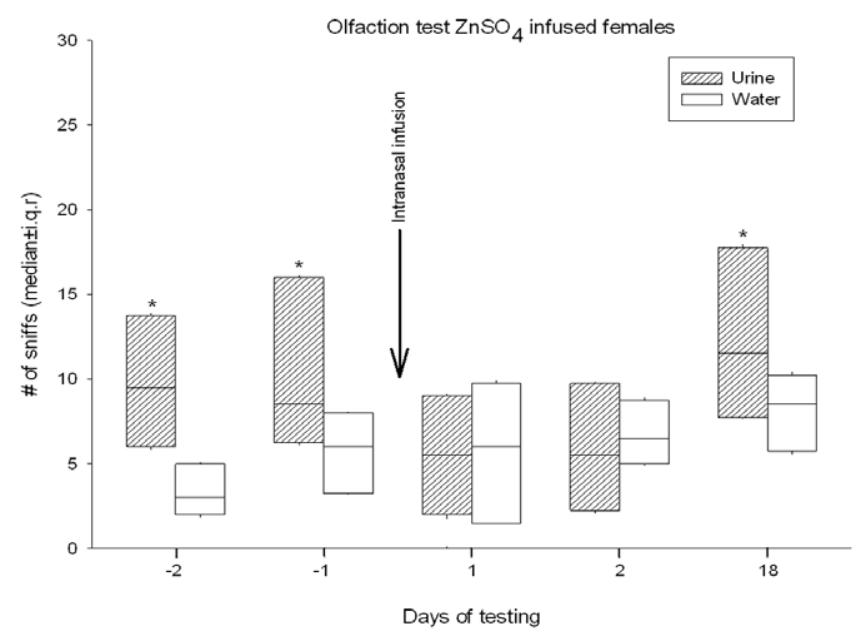

Figure 2: Number of sniffs directed at water or urine before and after the infusion of ZnSO4. ${ }^{*} \mathrm{p}<0.05$ vs water.

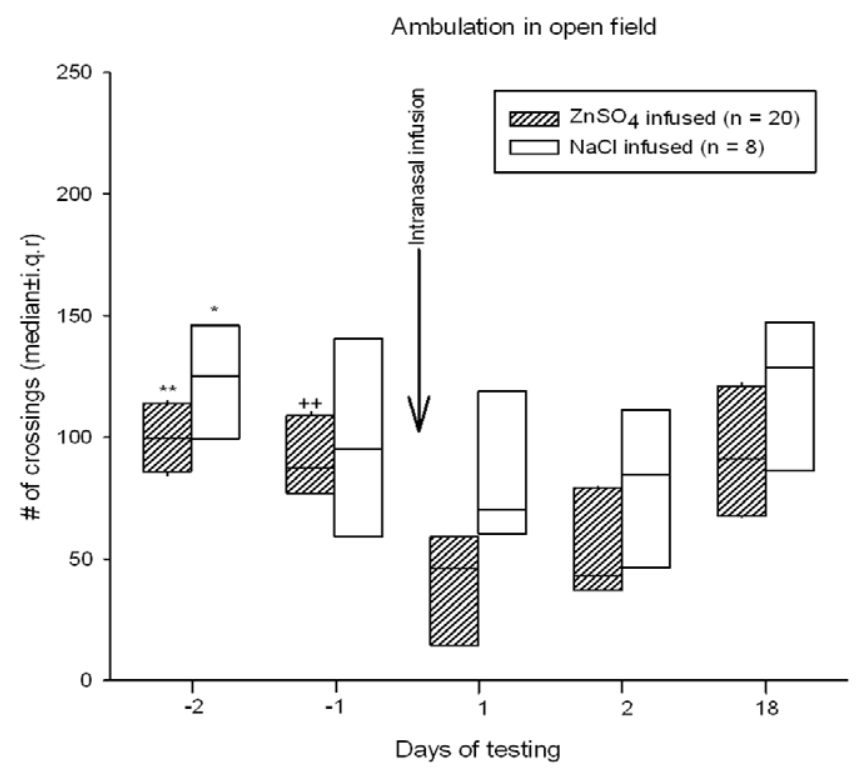

Figure 3: Number of crossings observed before and after the infusion of $\mathrm{NaCl}$ or ZnSO4. ${ }^{*} p<0.05,++p<0.01,{ }^{* *} p<0.001$ vs days 1 and 2 , same group.

day, resembling a free-running period shorter than $24 \mathrm{~h}$. Indeed, linear regression analysis of the lines adjusted to these patterns revealed that the values of $r$ were statistically significant for 8 out of 12 does $(p<0.05$, Table 2). It is interesting that in one doe (\#1985), in which the Rayleigh analysis indicated a significant circadian vector, the linear regression analysis did not reach statistical significance. This seems to be due to the successive back and forward shifts in the timing of nursing in this animal, which did not affect the rho value from the Rayleigh analysis but had a great influence on the $r$ value of the linear regression. Other anosmic virgins entered the nest box only on a few days (Table 1; Figure $7 \mathrm{~A}, \mathrm{~B})$ and, consequently, no statistical analysis could be performed on them. In contrast to the above-described differences in the frequency and time of day at which virgins displayed nursing behavior, whenever they entered the nest box and allowed suckling from the kits, they stayed inside for ca. 3-5 min, as occurs with lactating rabbits (Table 1). In summary, a total of 11 out of 20 virgin does sprayed with $\mathrm{ZnSO}_{4}$ (i.e., 55\%) showed nursing behavior in a fashion consistent with a periodicity of ca. $24 \mathrm{hrs}$, as determined through a Rayleigh analysis (three females) or a linear regression (eight rabbits).

The relationship between anosmia and the expression of nursing behavior on a given day was not a direct one. Table 3 shows that at the beginning of the experiment (early period) all females were anosmic on the day following the infusion of $\mathrm{ZnSO}_{4}$ (day 1), but only $21 \%$ of them (i.e., 4/20) showed nursing behavior two days later (day 3). By contrast, at the end of the experiment (late period) 60\% of $\mathrm{ZnSO} 4$ infused virgins (i.e., 12/20) showed nursing behavior (day 17), despite the fact that, on day 18 , only $1 / 20$ individuals (5\%) was anosmic.

\section{Discussion}

In agreement with our earlier report [8] the suckling stimulation provided by six kits allowed a normal time inside the nest box (i.e., ca.

$$
\text { Maternal responsiveness }
$$

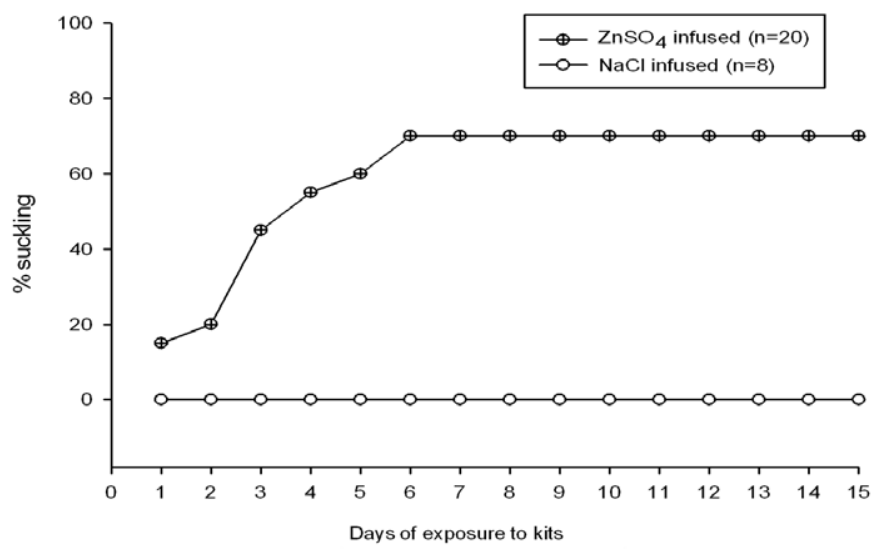

Figure 4: Proportion of virgins infused with $\mathrm{NaCl}$ or $\mathrm{ZnSO}_{4}$ that entered the nest box and crouched over the litter on each of the 15 days of daily exposure to foster kits. These percentages do not indicate that the same does entered the nest box on the days shown (see Table I for individual data).

\begin{tabular}{|c|c|c|c|c|c|c|c|c|}
\hline \# ㅇ & $\begin{array}{c}\text { First day } \\
\text { showing } \\
\text { nursing } \\
\text { behavior* }^{*}\end{array}$ & \begin{tabular}{|c|} 
Maximal \\
number of \\
consecutive \\
days \\
showing \\
nursing \\
behavior
\end{tabular} & & Rho & $p$ & $\begin{array}{c}\text { phase } \\
\text { angle } \\
(\alpha)\end{array}$ & $\begin{array}{c}\text { Geographic } \\
\text { hour }\end{array}$ & $\begin{array}{c}\% \\
\text { sucklings } \\
\text { in dark } \\
\text { phase }\end{array}$ \\
\hline 1951 & 1 & 3 & 3.58 & 0.522 & $<0.114$ & $28^{\circ}$ & 1.87 & 80 \\
\hline 2130 & 1 & 3 & 4.15 & 0.600 & 0.165 & $318^{\circ}$ & 21.2 & 29 \\
\hline 2045 & 1 & 13 & 5.93 & $\begin{array}{l}0.337 / \\
0.575\end{array}$ & $\begin{array}{l}<0.201 / \\
<0.014\end{array}$ & $\begin{array}{l}14^{\circ} \% \\
318^{\circ}\end{array}$ & 21.2 & 54 \\
\hline 1940 & 2 & 0 & 5.05 & 0.12 & $<0.87$ & $139^{\circ}$ & 9.27 & 40 \\
\hline 1944 & 3 & 8 & 6.78 & 0.220 & $<0.659$ & $87^{\circ}$ & 5.8 & 33 \\
\hline 1947 & 3 & 6 & 3.8 & 0.368 & $<0.245$ & $103^{\circ}$ & 6.87 & 44 \\
\hline 1996 & 3 & 3 & 5.45 & 0.725 & $<0.02$ & $45^{\circ}$ & 3.00 & 100 \\
\hline 1986 & 3 & 2 & 3.85 & 0.985 & nd & nd & nd & 100 \\
\hline 1989 & 3 & 0 & 3.37 & 0.767 & nd & nd & nd & 33 \\
\hline 1990 & 4 & 9 & 3.05 & 0.856 & $<0.001$ & $354^{\circ}$ & 23.6 & 100 \\
\hline 1985 & 4 & 7 & 2.67 & 0.661 & $<0.009$ & $105^{\circ}$ & 7.00 & 50 \\
\hline 1993 & 5 & 5 & 4.88 & 0.528 & $<0.085$ & $9^{\circ}$ & 0.60 & 82 \\
\hline 1959 & 6 & 2 & 7.05 & 0.545 & nd & nd & nd & 67 \\
\hline 1939 & 6 & 0 & 3.32 & 0.66 & nd & nd & nd & 0 \\
\hline
\end{tabular}

Table 1: Characteristics of nursing behavior and parameters determined through a Rayleigh analysis. 
Citation: González-Mariscal G, Lemus AC, Aguilar-Roblero R (2015) Contribution of Suckling Stimulation to the Daily Periodic Display of Nursing Behavior in Non-Lactating Virgin Rabbits. J Neurol Neurophysiol 6: 327. doi:10.4172/2155-9562.1000327
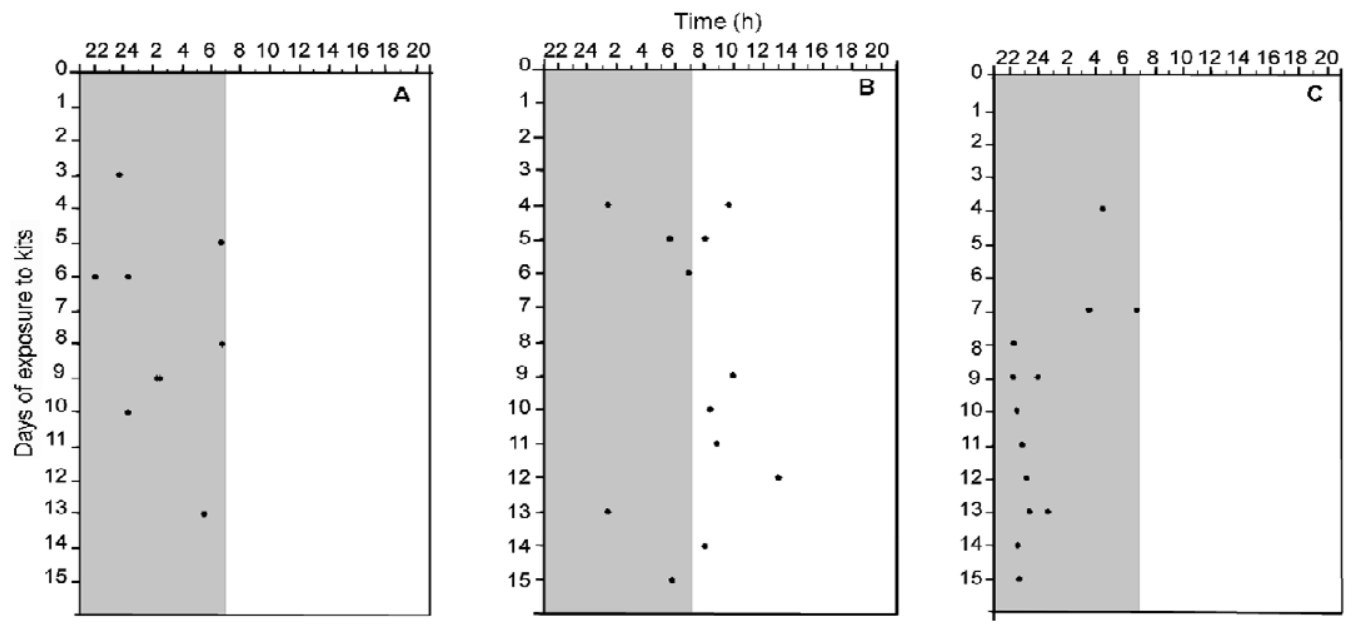

Figure 5: Actograms of the three virgins (a, b, c, corresponding to \#1996, 1985, and 1990 in Table I) from which we confirmed a circadian display of nursing behavior following a Rayleigh analysis.
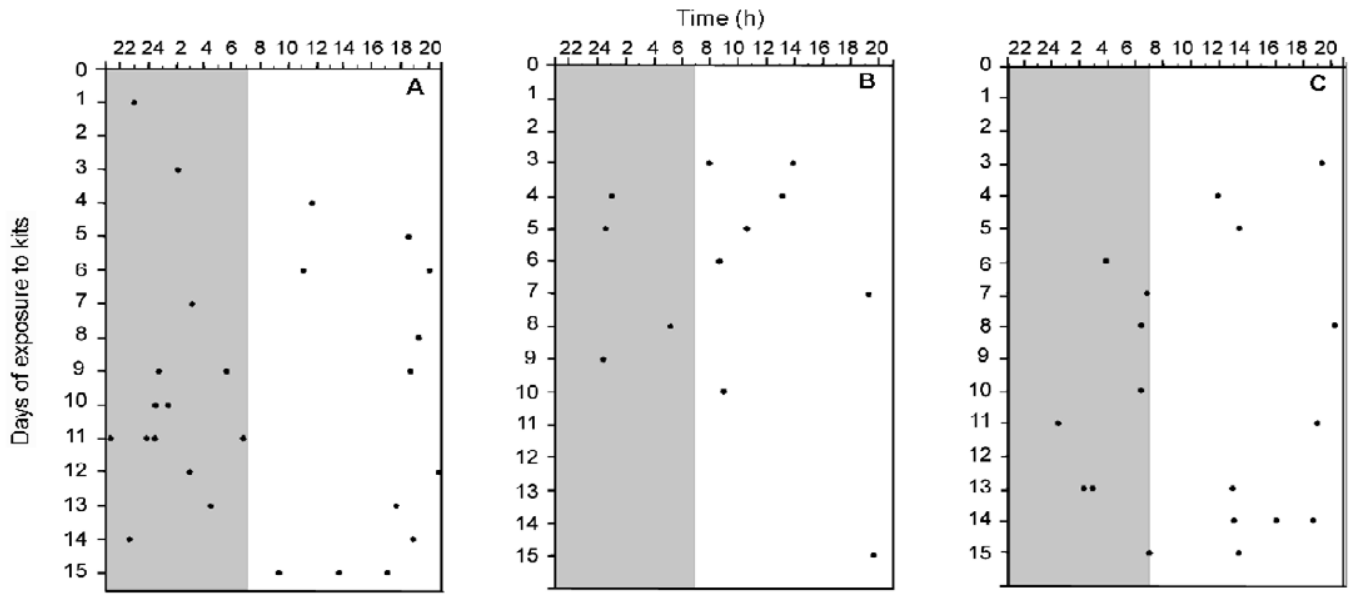

Figure 6: Actograms of three virgins (a, b, c, corresponding to \#2045, 1944, and 1947 in Table I) that entered the nest box several times a day, from which we could not determine a significant vector that confirmed circadian periodicity of nursing behavior.

\begin{tabular}{|c|c|c|c|c|}
\hline$\#+$ & slope & period & p & 0.9698 \\
\hline 1951 & -19.0 & 23.02 & 0.018 \\
\hline 2130 & 32.0 & 24.75 & 0.004 \\
\hline 2045 & -11.2 & 22.85 & 0.9467 \\
\hline 1940 & -59.0 & $23-57$ & 0.9669 \\
\hline 1944 & -10.9 & 22.84 & 0.9752 \\
\hline 1947 & -17.0 & 23.00 & 0.9071 \\
\hline 1996 & -6.0 & 22.65 & 0.9981 \\
\hline 1989 & -36.0 & 23.34 & 0.064 \\
\hline 1990 & -22.0 & 23.05 & 0.004 \\
\hline 1993 & 92.0 & 0.34 & 0.5329 \\
\hline
\end{tabular}

*does \# 1939 and 1959 were excluded from this analysis due to the few days on which they entered the nest box (see Table I)

Table 2: Linear regression analysis to determine circadian periodicity of nursing*

$3 \mathrm{~min}$ ) despite the virgins' incapacity to produce milk. Moreover, the consistency in the time spent inside the nest box is an indirect indicator that the kits provided did engage in suckling: we have shown that a threshold of suckling stimulation is essential to induce the crouching posture over the litter and to allow a normal time inside the nest box [8]. In contrast, the other characteristic of nursing behavior, i.e., 


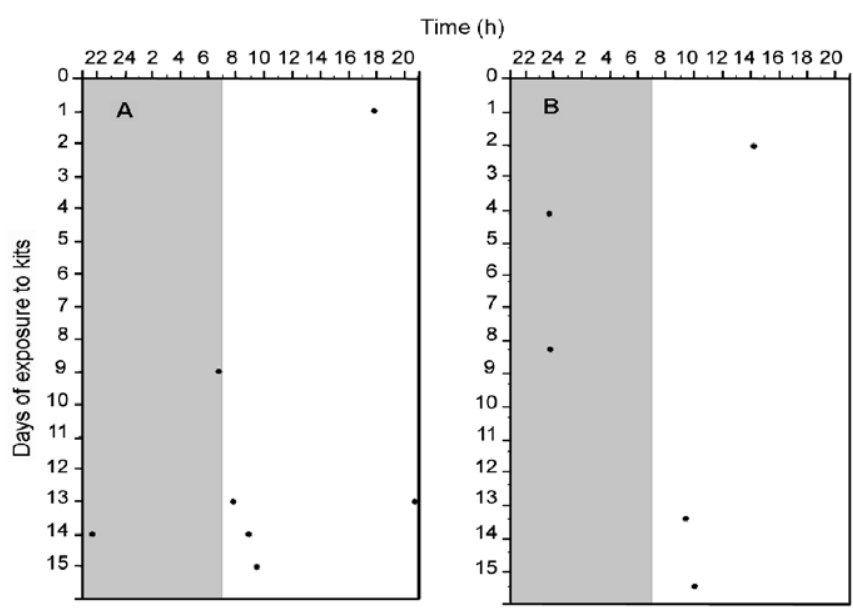

Figure 7: Actograms of two virgins (a, b, corresponding to \#2130 and 1940 in Table I) that entered the nest box only on five (out of 15) days of exposure to foster kits.

\begin{tabular}{|c|c|c|c|c|c|c|c|c|c|}
\hline \multirow{2}{*}{\multicolumn{2}{|c|}{ Early period }} & \multicolumn{3}{|c|}{$\begin{array}{c}\text { Percent } \\
\text { anosmic on } \\
\text { post-infusion } \\
\text { day } 1\end{array}$} & \multirow{2}{*}{\multicolumn{2}{|c|}{ Late period }} & \multicolumn{3}{|c|}{$\begin{array}{c}\text { Percent } \\
\text { anosmic on } \\
\text { post-infusion } \\
\text { day } 18\end{array}$} \\
\hline & & yes & no & Total & & & yes & no & Total \\
\hline \multirow{3}{*}{$\begin{array}{l}\text { Percent nursing } \\
\text { on post-infusion } \\
\text { day } 3\end{array}$} & Yes & 21 & 0 & 21 & \multirow{3}{*}{$\begin{array}{c}\text { Percent } \\
\text { nursing on } \\
\text { post-infusion } \\
\text { day } 17\end{array}$} & Yes & 7 & 53 & 60 \\
\hline & No & 79 & 0 & 79 & & No & 0 & 40 & 40 \\
\hline & Total & 100 & 0 & 100 & & Total & 7 & 93 & 100 \\
\hline
\end{tabular}

Table 3: Relationship between anosmia and display of nursing behavior in $\mathrm{ZnSO}_{4}-$ infused virgins.

its occurrence once a day with a period close to $24 \mathrm{~h}$ [4-6], differed from that of lactating mothers in the following aspects: a) the onset of nursing behavior was not immediate: most virgins started displaying it on the third to fourth day of pup exposure, i.e., on post-lesion days 5-6; b) none of the females entered the nest box every single day to crouch over the litter: the maximal number of consecutive days on which they showed nursing behavior ranged between 2 and 13; c) the proportion of virgin does sprayed with $\mathrm{ZnSO}_{4}$ that showed nursing behavior with a periodicity of ca. 24 hrs was $55 \%$ (11/20). Most of the nursing behavior episodes of these virgins occurred during the dark phase, as reported for mothers given free access to nurse their litters [5,6], despite the fact that we introduced the foster kits to virgins at $1000 \mathrm{hrs}$. That is, even though the virgins had access to the litters for $11 \mathrm{hrs}$ of the light period (i.e., from 1000 to $2100 \mathrm{hrs}$ ), they entered the nest box during the dark phase, as occurs in lactating rabbits $[5,6]$.

Although the present results confirm that anosmia promotes nursing behavior in virgin rabbits the mechanisms underlying this effect are unclear. Although $\mathrm{ZnSO}_{4}$ intranasal infusions reduced ambulation on the following two days this effect cannot explain the latency of 3-4 days to initiate nursing behavior because virgins infused with $\mathrm{NaCl}$ also showed such reduced ambulation but did not become ma 'ternal. Moreover, the fact that anosmia was present immediately after $\mathrm{ZnSO}_{4}$ infusions but nursing behavior was not and, vice versa, that at the end of the experiment up to $60 \%$ of lesioned virgins were maternal but only one was still anosmic, does not support a direct relationship between the perception of signals from the young and the likelihood of maternal responsiveness in virgin rabbits. Rather, we believe that the lesion to the olfactory mucosa (provoked by $\mathrm{ZnSO}_{4}$ infusions) may lead to the degeneration of fibers that interfere with the function of brain circuits that tonically inhibit the expression of maternal responsiveness in virgins. Indeed, there is evidence that the olfactory system inhibits 'abnormal' behaviors, specifically: lesions to the olfactory system promote the display of the lordosis reflex (characteristic of sexually receptive females) in castrated steroid-treated male rats [20,21].

Although the present results do not rule out a participation of milk output in timing the circadian periodicity of actual nursing they do show that such process is not essential. Perhaps milk output per se and/or the secretion of hormones like oxytocin and prolactin act together with nipple stimulation to activate a neural network that times the unfailing display of nursing with a periodicity of ca. $24 \mathrm{hrs}$. Indeed, the representation of the receptive field of the ventrum in cortical area $\mathrm{S} 1$ is larger in lactating rats than in virgins [22]. If something similar occurs in rabbits it may account for the larger variability in the display of nursing behavior of virgins vs lactating does.

A limitation of the present study is, of course, that a major difference between lactating mothers and 'maternal virgins' is that the latter have not been exposed to the hormones of pregnancy [2]. These agents 'prepare' the maternal brain to respond to the litter ab initio in a species-specific way. Thus, even primiparous rabbits upon first exposure to the young crouch over them inside the nest, nurse them for ca. $3 \mathrm{~min}$ [8] and repeat this activity with circadian periodicity [6]. Moreover, the activation of several forebrain nuclei following nursing (as determined by the number of c-FOS protein-immunoreactive cells) is the same on the first as on the seventh day of lactation [23]. Consequently, the lack of pregnancy hormones may partly account for the 'less than perfect' circadian timing of suckling behavior in maternal virgins. Another caveat of the present work is that, as the kits did not obtain any milk despite their suckling, we cannot determine how their tactile stimulation of the doe's ventrum or the intensity of the nipple stimulation provided compares to that of kits who do obtain milk. Moreover, we can anticipate that the release of PRL and OT by suckling was probably lower in these virgins than in truly lactating does. Clearly, more work is warranted to determine the relative contribution of milk output, hormones, and peripheral stimulation to the circadian display of rabbit nursing.

\section{Conclusion}

Our results show that suckling stimulation per se has a major role in timing the periodicity of nursing, even in the absence of a preceding pregnancy, and is sufficient to determine a normal duration of suckling episodes. That is, a neural network intrinsic to doe rabbits is activated by suckling stimulation, regardless of milk output, to allow the periodic expression of nursing behavior once a day. However, other factors, like milk output and the hormones of pregnancy and lactation, are necessary in most females to allow a 'flawless', unfailing display of nursing behavior like that observed in truly lactating rabbits.

This work was supported by CONACYT grants 128625 to GGM and 42993 to RAR.

\section{References}

1. Drewett RF, Kendrick KM, Sanders DJ, Trew AM (1982) A quantitative analysis of the feeding behavior of suckling rabbits. Dev Psychobiol 15: 25-32.

2. González-Mariscal G, Díaz-Sánchez V, Melo Al, Beyer C, Rosenblatt JS (1994) Maternal behavior in New Zealand white rabbits: quantification of somatic events, motor patterns, and steroid plasma levels. Physiol Behav 55 1081-1089.

3. Lincoln DW (1974) Suckling: a time-constant in the nursing behaviour of the rabbit. Physiol Behav 13: 711-714. 
Citation: González-Mariscal G, Lemus AC, Aguilar-Roblero R (2015) Contribution of Suckling Stimulation to the Daily Periodic Display of Nursing Behavior in Non-Lactating Virgin Rabbits. J Neurol Neurophysiol 6: 327. doi:10.4172/2155-9562.1000327

4. Jilge B (1995) Ontogeny of the rabbit's circadian rhythms without an external zeitgeber. Physiol Behav 58: 131-140.

5. Jilge B (1993) The ontogeny of circadian rhythms in the rabbit. J Biol Rhythms 8: 247-260.

6. González-Mariscal G, Lemus AC, Vega-Gonzalez A, Aguilar-Roblero R (2013) Litter size determines circadian periodicity of nursing in rabbits. Chronobiol In 30: 711-718.

7. Findlay AL, Tallal PA (1971) Effect of reduced suckling stimulation on the duration of nursing in the rabbit. J Comp Physiol Psychol 76: 236-241.

8. González-Mariscal G, Toribio A, Gallegos-Huicochea JA, Serrano-Meneses MA (2013b) The characteristics of suckling stimulation determine the daily duration of mother-young contact and milk output in rabbits. Dev Psychobiol 55: 809-817.

9. González-Mariscal G, Caba M, Martínez-Gómez M, Bautista A, Hudson R (2015) Mothers and offspring: the rabbit as a model system in the study of mammalian maternal behavior and sibling interactions. Horm Behav.

10. Meza E, Aguirre J, Waliszewski S, Caba M (2015) Suckling induces a daily rhythm in the preoptic area and lateral septum but not in the bed nucleus of the stria terminalis in lactating rabbit does. Eur J Neurosci 41: 196-204.

11. Findlay AL, Roth LL (1970) Long-term dissociation of nursing behavior and the condition of the mammary gland in the rabbit. J Comp Physiol Psychol 72: 341-344.

12. Chirino R, Beyer C, González-Mariscal G (2007) Lesion of the main olfactory epithelium facilitates maternal behavior in virgin rabbits. Behav Brain Res 180: 127-132

13. Schaal B, Coureaud G, Langlois D, Giniès C, Sémon E, et al. (2003) Chemical and behavioural characterization of the rabbit mammary pheromone. Nature 424: 68-72.

14. Hudson R, Distel H (1983) Nipple location by newborn rabbits: behavioura evidence for pheromonal guidance. Behaviour 85: 260-274.

15. Hudson R, Melo Al, González-Mariscal G (1994) Effect of photoperiod and exogenous melatonin on correlates of estrus in the domestic rabbit. J Comp Physiol A 175: 573-579.

16. Portaluppi F, Smolensky MH, Touitou Y (2010) Ethics and methods for biological rhythm research on animals and human beings. Chronobiol Int 27 1911-1929.

17. Mulvaney BD, Heist HE (1971) Regeneration of rabbit olfactory epithelium. Am J Anat 131: 241-251.

18. Siegel S, Castellan NJ (1988) Non-parametric statistics for the behaviora sciences. Mc Graw Hill, New York.

19. Batschelet E (1981) Circular statistics in biology. Academic Press, London.

20. Schaeffer C, Roos J, Aron C (1986) Accessory olfactory bulb lesions and lordosis behavior in the male rat feminized with ovarian hormones. Horm Behav 20: 118-127.

21. Schaeffer C, Roos J, Aron C (1990) Lordosis behavior in intact male rats: effects of hormonal treatment and/or manipulation of the olfactory system. Horm Behav 24: 50-61.

22. Xerri C, Stern JM, Merzenich MM (1994) Alterations of the cortical representation of the rat ventrum induced by nursing behavior. J Neurosci 14: 1710-1721.

23. González-Mariscal G, Jiménez A, Chirino R, Beyer C (2009) Motherhood and nursing stimulate c-FOS expression in the rabbit forebrain. Behav Neurosci 123: $731-739$ 